\title{
A Randomized, Controlled Trial of Linopirdine in the Treatment of Alzheimer's Disease
}

\author{
Kenneth Rockwood, B. Lynn Beattie, M. Robin Eastwood, Howard Feldman, \\ Erich Mohr, William Pryse-Phillips and Serge Gauthier
}

\begin{abstract}
Objectives: We tested the efficacy and safety of linopirdine, a novel phenylindolinone, in the treatment of Alzheimer's disease. Methods: A multicentre, randomized, double-blind, parallel group, placebo-controlled trial of linopirdine ( $30 \mathrm{mg}$ three times per day or placebo). Patients ( $\mathrm{n}=382$, $55 \%$ male, $98 \%$ Caucasian, age range 51-95 years) with mild or moderate Alzheimer's disease, of whom 375 received at least one treatment dose were analysed. There were no important differences between the groups at baseline. Results: No difference was seen in Clinical Global Impression scores between patients receiving placebo and those receiving linopirdine $(n=189)$. Small differences in the Alzheimer's Disease Assessment Scale-Cognitive Subscale (ADAS-Cog) scores were seen throughout the study favouring linopirdine; at 6 months the ADAS-Cog scores were 20.2 (linopirdine) and 22.1 (placebo) $p=0.01$. Conclusions: This trial did not detect clinically meaningful differences in patients receiving linopirdine for 6 months, despite evidence of a small degree of improved cognitive function. Further studies may benefit from more sensitive tests of treatment effects in Alzheimer's disease.
\end{abstract}

RÉSUMÉ: Étude randomisée, contrôlée, de la linopirdine dans le traitement de la maladie d'Alzheimer. But: L'objectif de l'étude était d'évaluer l'efficacité et la sécurité de la linopirdine, une nouvelle phénylindolinone, dans le traitement de la maladie d'Alzheimer. Méthodes: Il s'agit d'une étude multicentre, randomisée, en double-insu, avec groupes parallèles et contrôlée par placebo. La linopirdine ou un placebo était administré à la dose de $\mathbf{3 0} \mathrm{mg}$ trois fois par jour chez des patients $(\mathrm{n}=382$, dont $55 \%$ étaient des hommes, $98 \%$ étaient caucasiens, dont l'âge variait de 51 à 95 ans) atteints de maladie d'Alzheimer légère ou modérée. Les observations sur 375 patients ayant reçu au moins une dose de la médication à l'étude ont été analysées. Il n'y avait pas de différence importante entre les groupes à l'évaluation initiale. Résultats: Nous n'avons pas observé de différence dans le score d'impression clinique globale entre les patients recevant le placebo et ceux recevant la linopirdine $(n=189)$. Pendant toute la durée de l'étude, il existait de petites différences dans les scores de l'échelle d'évaluation de la maladie d'Alzheimer - sous-échelle cognitive - en faveur de la linopirdine; à 6 mois, les scores étaient de 20.2 (linopirdine) et 22.1 (placebo) $\mathrm{p}=0.01$. Conclusions: Cette étude n'a pas détecté de différence cliniquement significative chez les patients recevant la linopirdine pendant 6 mois, malgré l'observation d'une légère amélioration de la fonction cognitive. Des études ultérieures auraient avantage à utiliser des tests plus sensibles pour détecter les effets du traitement dans la maladie d'Alzheimer.

Can. J. Neurol. Sci. 1997; 24: 140-145

Alzheimer's disease is common, ${ }^{1,2}$ greatly feared ${ }^{1}$ and costly. ${ }^{3,4}$ Effective treatment of Alzheimer's disease remains limited $^{5-15}$ Our group was therefore interested in testing new treatments of this type of dementia.

Linopirdine, a novel phenylindolinone compound, appeared to be a promising agent. Like many experimental Alheimer's disease treatments, it increases release of acetylcholine. In contrast to other agents which inhibit acetylcholinesterase (AChE), linopirdine appears to selectively enhance physiologic ACh release. ${ }^{16-18}$ In consequence, it was felt to have the potential to avoid the side-effects of AChE inhibitors which arise from chronic postsynaptic stimulation. ${ }^{18}$ In addition, it enhances release of noradrenaline and serotonin, ${ }^{16}$ both of which have been reported to be decreased in Alzheimer's disease. ${ }^{11,14}$
We report the results of a randomized, controlled study of the efficacy and safety of linopirdine in the treatment of Alzheimer's disease.

From the Division of Geriatric Medicine and Department of Community Health \& Epidemiology, Dalhousie University, Halifax (K.R.); Division of Geriatric Medicine, University of British Columbia, Vancouver (B.L.B.); Departments of Psychiatry and Preventive Medicine \& Biostatistics, University of Toronto, Toronto (M.R.E.);

Division of Neurology, University of British Columbia, Vancouver (H.F.); Division of Neurology, University of Ottawa, Ottawa (E.M.); Division of Neurology, Memorial

University of Newfoundland, St. John's (W.P.P.); McGill Centre for Studies on Aging, McGill University, Montreal (S.G.)

RECEIVED JULY 10, 1996. ACCEPTED IN FINAL FORM JANUARY 6, 1997.

Reprint requests to: Kenneth Rockwood, Centre for Health Care of the Elderly, Queen Elizabeth II Health Sciences Centre, 5955 Jubilee Road, Halifax, Nova Scotia B3H 2E1 


\section{Methods}

\section{Design, sample size, duration}

The study was designed by the sponsor, DuPont Pharma and modified, after discussion with the investigators, to include a measure of independence in personal care.

We employed a randomized, double-blind, parallel group, placebo-controlled design. This was a Phase III trial. The main outcome measures of efficacy, as detailed below, were clinically important change, as measured by the Clinical Global Impression (CGI) and improved cognitive function, as measured by the Alzheimer's Disease Assessment Scale - Cognitive Subscale (ADAS-Cog).$^{19}$ Assuming a standard deviation of 4, we calculated that 160 patients per group would be required to have $90 \%$ power to detect a 1.6 difference (felt clinically to be represent an important effect) in the ADAS-Cog score at 6 months, at the 0.05 significance level. ${ }^{20}$

\section{Measures}

The primary clinical outcome measure, the CGI, is a 7 point, semi-quantitative scale of the change in the patients' condition compared with study entry. It is scored so that $1=$ very much improved; $4=$ no change, and; $7=$ very much worse, with descriptors of "much" and "minimal" change for the other points. This rating was performed by the clinician with knowledge of the caregivers' and nurses' observations, but blind to the psychometric scores. The primary cognitive outcome measure, the ADAS-Cog, provides a performance-based assessment of memory, language, visuospatial skills, praxis and orientation. For the study to have established benefit of linopirdine over placebo a statistically significant difference in both the proportion of patients improving and in the ADAS-Cog scores at 6 months compared with baseline would have been required.

Six secondary measures were incorporated in this study. The ADAS noncognitive scale (ADAS-Noncog) measures behavioural aspects such as mood, behaviour, motor activity, thought content and vegetative symptoms. These data were collected based on test performance and an account from the carer of the patient's behaviour in the week prior to testing. The Syndrome Kurtz Test (SKT) is a psychometric battery of nine subtests designed to measure attention, memory and language and learning functions. ${ }^{21}$ The Folstein Mini-Mental State Examination (MMSE) was also administered. ${ }^{22}$ Functional capacity was measured using the Lawton-Brody Instrumental Activities of Daily Living (IADL) scale, and the Physical Self-Maintenance Scale (PSMS). ${ }^{23}$ Behavioural disturbances were measured using the Dementia Behavioural Disturbance Scale (DBDS). ${ }^{24}$ This 28 item questionnaire was completed by carers, in reference to changes in the patients' behaviour from baseline. Like the IADL, PSMS, and ADAS, the DBDS is scored so that at higher score is consistent with worse dementia.

Safety was measured by a recording of adverse clinical events, including abnormal test results in laboratory data and electrocardiograms. Safety visits were carried out in conjunction with efficacy assessments at entry, baseline, and days 15, 29, 43, 71, 99, 127, 155 and 183.

\section{Patients and Randomization Procedure}

Patients with mild to moderate Alzheimer's disease, as defined using DSM-III- $\mathrm{R}^{25}$ and the McKhann criteria ${ }^{26}$ were eligible for treatment if their MMSE scores were between 15 and
24 , inclusive. Patients were excluded if they had a past history of a major affective disorder or schizophrenia, or evidence of dementia not caused by Alzheimer's disease, including vascular dementia. Specifically, patients with a Hachinski ischaemia score $^{27}$ of 4 or more, and those with a history of stroke, or of clinically significant carotid or vertebral-basilar stenosis or plaque, or a CT or MRI scan demonstrating prior stroke or widespread lacunar lesions were excluded. Also excluded were patients with clinically significant mass lesions, or focal EEG changes, and those with a history of significant alcohol or drug abuse. Patients with hallucinations, or visual or auditory problems which would interfere with testing were excluded. Concomitant medications for any other central nervous system disorder were not allowed.

Patients were randomized upon entry into the study. All 382 patients entered a two week, single-blind placebo lead-in to establish baseline measurement, carried out at the end of this period, followed by double-blind, randomized treatment. Randomization of patients was stratified based on their MMSE score at study entry, with scores of 14-18 = moderate and 19-24 $=$ mild. Medications were assigned in blocks of 4 within each stratum at each centre.

\section{Analysis}

Efficacy data were analysed for all patients who had a baseline assessment and at least one assessment during randomized treatment, using an intention-to-treat analysis. For the two primary outcome measures we report data from baseline and each visit over the six months. The last observation from a scheduled protocol visit is carried forward as the endpoint for patients on whom no data are available at month 6 . Data for secondary measures are reported at baseline and at endpoint. The analysis of safety data included all patients who had received at least one dose of study medication.

The data were analysed using the SAS software package. ${ }^{28}$ The analyses runs were conducted by the Biometrics Section of DuPont Merck Pharmaceuticals at Wilmington, Delaware. The CGI data were dichotomized as improved / not improved and compared between treatments using Fisher's exact test. Ninetyfive per cent confidence intervals were calculated for the percentage of patients improved / not improved in each group. Differences between treatment groups in change from baseline for all other efficacy data were analysed using an analysis of covariance model, with site and treatment effects and covariate adjustments for age, sex and baseline MMSE score. Safety data were analysed using chi-square for categorical data, and t-test for continuous data. The critical probability of Type I error was set at $\mathrm{p} \quad 0.05$. Given that the sample was not designed to detect differences in the groups before treatment, tests of the statistical significance of differences in the treatment groups at baseline are not reported.

\section{Ethics}

This protocol was approved by the research and ethics committees of the participating sites. Informed consent was obtained in each case.

\section{Results}

There were no important differences in demographic and clinical characteristics at baseline between the two groups (Table 1). Figure 1 reports assignments and withdrawals by 
treatment status. In total, 20 of the placebo patients $(10.5 \%$, including 7 who withdrew during the placebo lead-in period) and 61 of the linopirdine patients $(31.6 \%)$ discontinued prior to completing the six months of randomized treatment ( $\mathrm{p} \quad 0.05$ ). The most common reason for discontinuation of treatment was the occurrence of an adverse event, as detailed below.

Table 1: Summary of demographic and clinical characteristics of the sample at baseline, by treatment status.

\begin{tabular}{lll}
\hline Variable & Placebo $\mathbf{n}=\mathbf{1 8 9}$ & Linopirdine $\mathbf{n}=\mathbf{1 9 3}$ \\
Mean age \pm s.d. & $71.5 \pm 7.9$ & $71.7 \pm 7.6$ \\
n (\%) Caucasian & $186(98)$ & $189(98)$ \\
n (\%) Female & $100(53)$ & $115(60)$ \\
n (\%) Right-handed & $178(94)$ & $192(99)$ \\
n (\%) Living alone & $15(8)$ & $13(7)$ \\
Mean years education \pm s.d. & $11.2 \pm 3.6$ & $11.1 \pm 3.8$ \\
Mean MMSE score \pm s.d. & $19.6 \pm 3.1$ & $19.4 \pm 3.1$ \\
Mean Hachinski Index \pm s.d. & $1.1 \pm 0.9$ & $1.1 \pm 1.0$ \\
$\%$ Borderline dementia & $4(2.1 \%)$ & $3(1.6 \%)$ \\
$\%$ Mild dementia & $82(43.6 \%)$ & $83(43.0 \%)$ \\
\% Moderate dementia & $101(53.7 \%)$ & $104(53.9 \%)$ \\
$\%$ Severe dementia & $1(0.5 \%)$ & $3(1.6 \%)$ \\
\hline
\end{tabular}

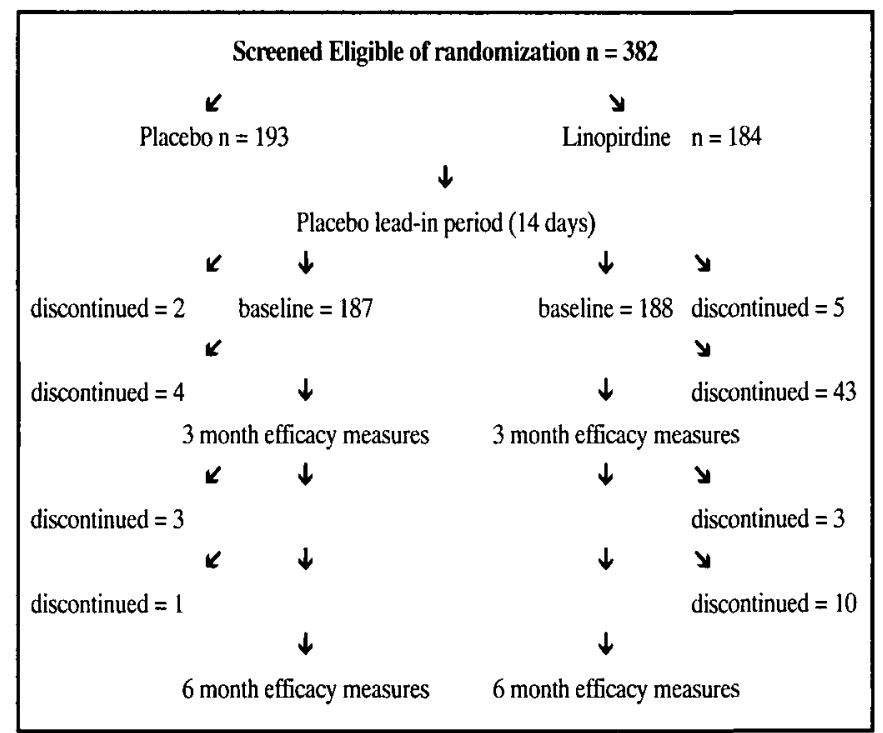

Figure 1: Summary of randomization and withdrawals
Figure 2 reports the distribution of clinically important change, according to the global clinical impression, at each visit and at the endpoint. As can be seen, the proportion of patients with some degree of improvement was initially similar in both the treatment and control groups, but declined at six months. It is of note that comparatively few patients deteriorated.

Figure 3 presents the ADAS-Cog data over the course of the study. The ADAS-Cog detected significant improvement from baseline to three months of treatment, and also demonstrated decline in the placebo group at six months.

Table 2 summarizes the mean values of the secondary measures. The total ADAS score resembled the ADAS-Cog scores. The ADAS Non-cog, SKT, IADL, DBDS and MMSE scores deteriorated in both groups.

Adverse clinical events occurred in $63 \%$ of placebo patients and $65 \%$ of patients treated with linopirdine. New-onset adverse clinical events deemed to be treatment-related occurred in 68 $(36 \%)$ of patients treated with placebo and $77(41 \%)$ of patients receiving linopirdine. The only adverse clinical event occurring significantly more often in linopirdine patients than in those receiving placebo was elevations of the liver function tests. Overall, $47.3 \%$ of linopirdine patients but only $4.8 \%$ of placebo patients had at least one alanine transferase (ALT) elevation above the normal range ( $p \quad 0.05$ ). Elevation of ALT more than three times the upper limit of normal was seen in 37 (19.9\%) of patients receiving linopirdine, but only $2(1.6 \%)$ of controls. Elevated ALT levels were detected within two months of the first dose in $27(73 \%)$ of patients who had increases more than three times normal. The mean length of dosing until onset of a three times elevation was 51.4 days. The mean duration of elevation was 25.8 days. No patient had persistently elevated liver enzymes, but 24 discontinued treatment due to ALT elevations. The reasons for early termination are summarized in Table 3.

\section{Discussion}

This study failed to detect a consistent, clinically meaningful difference between patients with mild to moderate Alzheimer's disease treated with linopirdine and those receiving placebo. There were nevertheless trends favouring treatment in one of the primary outcome measures (the ADAS-Cog) which reached statistical significance by the end of the trial. Is this "negative" trial due to an inefficacious compound, or due to methodologic problems in detecting treatment effects in Alheimer's disease?

Many important methodologic controversies arose during the

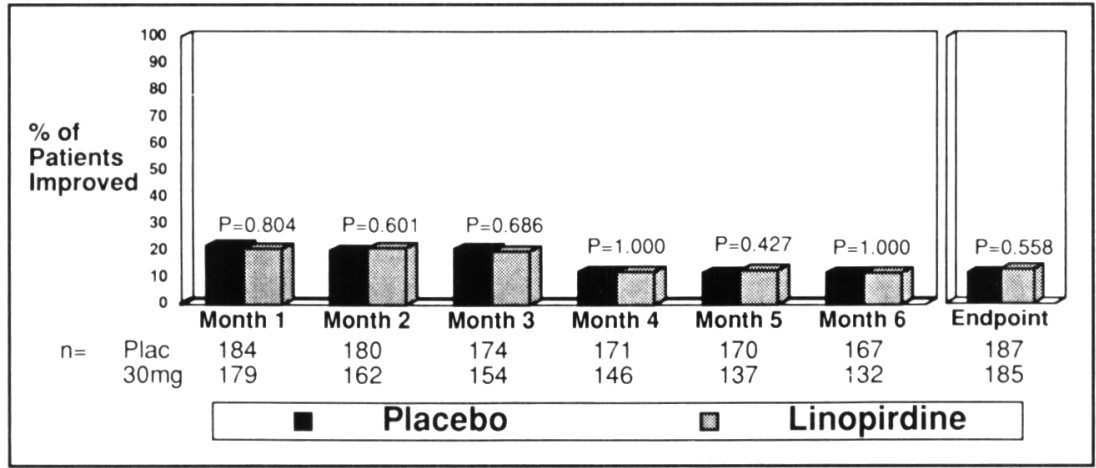

Figure 2: Proportion of patients improved, according to the Clinical Global Impression. 


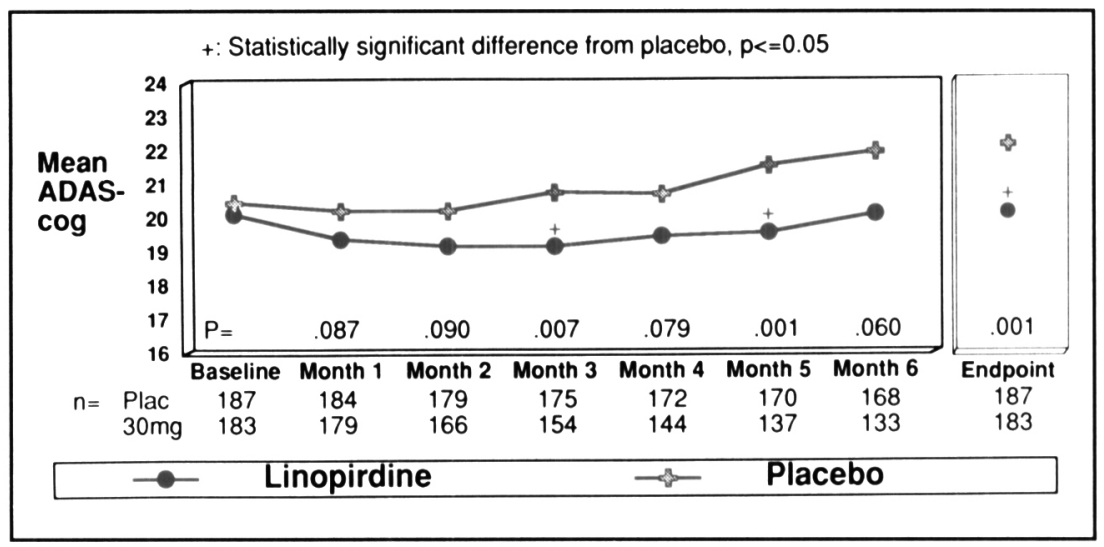

Figure 3: Mean ADAS-Cog scores, by treatment group.

Table 2: Summary of mean ( \pm S.E.M.) values for the secondary outcome measures at baseline and at endpoint, by treatment status.

\begin{tabular}{lcccc}
\hline & \multicolumn{2}{c}{ Baseline } & \multicolumn{2}{c}{ Endpoint } \\
\hline & $\begin{array}{c}\text { Placebo } \\
\mathrm{n}=187\end{array}$ & $\begin{array}{c}\text { Linopirdine } \\
\mathrm{n}=183\end{array}$ & $\begin{array}{c}\text { Placebo } \\
\mathrm{n}=187\end{array}$ & $\begin{array}{c}\text { Linopirdine } \\
\mathrm{n}=183\end{array}$ \\
\hline ADAS Non-Cognitive Test & 2.4 & 2.3 & $3.4 \pm 0.9$ & $3.0 \pm 0.8$ \\
& \pm 2.6 & \pm 2.6 & & \\
ADAS Total score & 22.8 & 22.6 & $25.4 \pm 2.6$ & $23.2 \pm 0.7^{*}$ \\
& \pm 9.5 & \pm 10.0 & & \\
Syndrome Short Test (SKT) & 38.5 & 37.8 & $40.8 \pm 2.4$ & $39.5 \pm 1.5$ \\
& \pm 6.3 & \pm 6.7 & & \\
Instrumental Activities of Daily Living & 19.8 & 19.1 & $21.2 \pm 1.4$ & $20.1 \pm 1.0$ \\
& \pm 5.1 & \pm 5.2 & & \\
Dementia Behaviour Disturbance Scale & 14.7 & 14.3 & $15.7 \pm 1.1$ & $14.9 \pm 0.6$ \\
& \pm 9.7 & \pm 9.6 & & \\
\hline
\end{tabular}

* Probability of difference in linopirdine versus placebo $<0.05$.

Table 3: Summary of early terminations from the study, after baseline, by treatment status.

\begin{tabular}{lll}
\hline Reason for early termination & $\begin{array}{l}\text { Placebo } \\
\mathbf{n = 1 8 3}\end{array}$ & $\begin{array}{l}\text { Linopirdine } \\
\mathbf{n = 1 8 7}\end{array}$ \\
\hline Adverse clinical event & $4(2 \%)$ & $41(21 \%)^{*}$ \\
$\quad$ Liver function test & $0--$ & $24(12 \%)^{*}$ \\
$\quad$ Other & $4(2 \%)$ & $17(9)$ \\
Concurrent illness & $2(1 \%)$ & $2(1 \%)$ \\
Administrative & $1(1 \%)$ & $1(1 \%)$ \\
Withdrew consent & $7(4 \%)$ & $8(4 \%)$ \\
Other $* *$ & $6(3 \%)$ & $9(5 \%)$ \\
\hline
\end{tabular}

* Probability of difference between linopirdine and placebo $<0.05$.

** Other reasons include behavioural problems (9) and loss of caregiver (3).

course of this trial which, designed in 1991, was carried out at a comparatively early stage of testing of anti-dementia compounds. The most important controversy was that of the choice of outcome measures. As described elsewhere, then, as now, the regulatory fashion was to use two primary outcome measures: one a global clinical assessment, the other, an objective, performance-based cognitive test. ${ }^{29,30}$ The rationale for the use of these two measures is to ensure that clinically trivial but statistically significant differences in cognitive test performance not provide the basis of regulatory approval for anti-dementia compounds. This reflects concern about the relevance of cognitive test performance to the patient's quality of life.

For many reasons, this concern appears to be well founded, ${ }^{29-32}$ but the solution - an untutored and unstandardized global clinical measure - may not be. The arguments for and against the use of global measures have been dealt with in more detail elsewhere. ${ }^{29,31}$ However refined such theoretical arguments may become, they would benefit from data about test performance. ${ }^{33}$ Of note, the trends seen in the ADAS-Cog, SKT and IADL provide evidence for convergent construct validation: i.e., all the measures changed in the same way, suggesting that the ADASCog result is valid. Given that the sample size was large enough to detect small changes, the current study is likely to represent a stable estimate of the effect size of linopirdine at six months.

Almost one-third of the treatment group withdrew over the course of the trial, compared with only $10.5 \%$ of those receiving a placebo. None of the patients in the placebo group, but 24/187 treated withdrew due to elevated ( $>3$ times normal) transaminase levels. This level of withdrawal is somewhat less than in the 
tacrine studies, in which $25 \%$ have had ALT concentration more than three times the upper limit of normal, ${ }^{34}$ although this has varied between studies. ${ }^{5-10}$ Apart from its importance as a safety outcome, this finding potentially threatens the internal validity of the study. We found no important differences, however, between those withdrawing from the two groups, so that the initial equivalence of the groups appears to have still obtained at six months. In any event, the last-observation-carried-forward method is one safeguard against differential withdrawal effects.

Are there circumstances under which the compound might be more effective? On the face of it, the data do not support an extension of the time frame of the study, because there was decline in functioning in both groups. On the other hand, less than half the patients deteriorated. Whether the placebo effect can be maintained beyond six months is not clear, but our experience suggests that longer antidementia trials are more likely to give insight into clinical effectiveness. There may be a false dichotomy between "neuroenhancing" and "neuroprotective" drugs, suggesting that trials of either type should be carried out long enough for differential rates of worsening to be detected.

Finding even modest evidence of benefit gives rise to the question of "responders" and "non-responders" to a drug. The sample was stratified to include a mildly demented and a moderately demented group. This subgroup analysis showed a somewhat more favourable drug effect in those with moderate impairment, but no clear-cut differences in response emerged across all measures. An analysis restricted to patients who completed the six months of the trial failed to detect significant differences between the groups.

Stratification of dementia severity was done according to the MMSE score. The use of the MMSE score to define inclusion and exclusion and exclusion criteria is controversial. Two questions arise: is the MMSE score a sensitive and specific marker of dementia, and; does the score vary by dementia severity? The answer to the first question is clear: the measurement properties of the MMSE vary with the level of education of the subject. ${ }^{35-41}$ Thus the use of 24 as an upper level beyond which subjects should be excluded as not having dementia is clearly unacceptable, as it will exclude more highly educated subjects with dementia. This is reflected in the trials in which the C5R has subsequently participated, none of which have used 24 as an upper cut-point.

The relationship between the total MMSE score and dementia severity seems to be somewhat less influenced by education. A post-hoc cluster analysis, using Ward's minimum variance technique to identify clusters, ${ }^{42}$ was performed using the baseline MMSE, ADAS-Cog, ADAS-Noncog, and CGI scores, as well as age and sex. This identified a group with more severe disease, as measured by the ADAS-Cog, ADAS-Noncog, SKT and DBDS. Of the 103 patients in this cluster, $94 \%$ had been randomized in the moderate strata, suggested that the $18 / 19$ cutpoint on the MMSE was useful in distinguishing between mild and moderate impairment. Nevertheless, as evidenced in Table 1, a few patients with scores within this range had more than moderate (i.e., "severe") or less than mild (i.e., "borderline") dementia, as assessed by the clinical impression of disease severity.

Although this was a Phase III trial, the proportion of patients seen at the clinics of the participating centres who could actually be enrolled in the trial was quite small, and varied between $10-$ $20 \%$ of the subjects screened. This problem is not limited to anti-dementia drug trials, but particularly reflects the practical difficulties of doing trials in older patients, who are more likely to have comorbid disease. The demonstration of efficacy is not likely to be independent of the inclusion and exclusion criteria. A more "pure" sample will be more likely to demonstrate efficacy, but it will also be less representative of patients with Alzheimer's disease. In consequence, we believe that there is merit in holding these trials to a high standard.

\section{ACKNOWLEDgements}

This work was supported by a grant from Dupont Pharma, Mississauga, Ontario. Dr. Rockwood is supported by the National Health Research Development Program through a National Health Scholar award.

\section{Participating Centres}

In addition to the authors, the following sites and investigators participated in the trial:

Peter Bailey, Saint John Regional Hospital, Saint John

Howard Bergman, Jewish General Hospital, Montreal

Sandra Black, Sunnybrook Hospital, Toronto

Remy Bouchard, Université Laval, Ouébec

Albert Lamontagne, Université de Sherbrooke, Sherbrooke

Helene Masson, Hôpital Notre-Dame, Montréal

Peter McCracken, Edmonton General Hospital, Edmonton

M.P.V. Nair, McGill University, Montreal

Irma Parhad, Foothills Hospital, Calgary (deceased)

Neelan Pillay, University of Manitoba, Winnipeg

Ali Rajput, University Hospital, Saskatoon

Alain Robillard, Hôpital Maisonneuve-Rosemount, Montréal

Jonathan Willmer, Elizabeth Bruyere Centre, Ottawa.

\section{REFERENCES}

1. Canadian Study of Health and Aging Working Group. Canadian Study of Health and Aging: methods and prevalence of dementia. Can Med Assoc J 1994; 150: 899-914.

2. Rockwood K, Stadnyk K. the prevalence of dementia in the elderly: a review. Can J Psychiatry 1994; 39: 253-257.

3. Hay JW, Ernst RL. The economic cost of Alzheimer's disease. Am J Public Health 1987; 77: 1169-1175.

4. Ostbye T, Crosse E. Net economic cost of dementia in Canada. Can Med Assoc J 1994; 151: 1457-1564.

5. Knapp MJ, Knopman DS, Solomon PR, et al. A 30-week randomized controlled trial of high-dose tacrine in patients with Alzheimer's disease. JAMA 1994; 268: 2546-2565.

6. Farlow M, Gracon SJ, Hershey LA, et al. A controlled trial of tacrine in Alzheimer's disease. JAMA 1991; 268: 2564-2565.

7. Davis KL, Thal LJ, Gamzu ER, et al. A double-blind placebo-controlled multicentre study of tacrine for Alzheimer's disease. $\mathrm{N}$ Engl J Med 1992; 327: 1253-1259.

8. Eagger SA, Levy R, Sahakiar RJ. Tacrine in Alzheimer's disease. Lancet 1991; 337: 989-992.

9. Chatellier G, Lacomble ZL. Tacrine and lecithin in senile dementia of the Alzheimer type: a multicentre trial. Br Med J 1990; 300: 495-499.

10. Guathier S, Bouchard R, Lamontagne A, et al. Tetrahydroaminoacradine-lecithin combination treatment in patients with intermediate-stage Alzheimer's disease. N Engl J Med 1990; 322: $1272-1276$.

11. Mohr E, Schlegel J, Iabbrini G, et al. Clonidine treatment of Alzheimer's disease. Arch Neurol 1989; 46: 376-378.

12. Parnetti L, Senin U, Carosi M, Baasch H. Mental deterioration in old age: results of two multicentre, clinical trials with nimodipine. Clin Ther 1993; 15: 394-406.

13. Saletu B, Paulus E, Linzmayer L, et al. Nicergoline in senile dementia of Alzheimer type and multi-infarct dementia: a double-blind, placebo-controlled, clinical and EEG/ERP mapping study. Psychopharmacol (Berl) 1995; 117: 385-395. 
14. Cutler NR, Havby J, Kay AD, et al. Evaluation of zimeldine in Alzheimer's disease: cognitive and biochemical markers. Arch Neurol 1985; 42: 744-748.

15. Schneider LS, Olin JT. Overview of clinical trials of hydergine in dementia. Arch Neurol 1994; 51: 787-798.

16. Cook L, Nickolson VJ, Steinfels GF, et al. Cognition enhancement by the actelycholine releaser DUP 996. Drug Develop Res 1990; 19: 301-314.

17. Nickolson VJ, Tam SW, Myers MJ, Cook L. DuP 996 (3,3-Bis(4Pyrindinylmethyl)-1-Pheylindolin-2-One) enchances the stimulus-induced release of acetylcholine from rat brain in vitro and in vivo. Drug Develop Res 1990; 19: 285-300.

18. DeNoble VJ, DeNoble KF, Spencer KR, et al. Comparison of DuP 996, with physostigmine, THA and 3,4-DAP on hypoxia-induced amnesia in rats. Pharmacol Biochem Behav 1990; 36: 957-961.

19. Rosen WG, Mohs RC, Davis KL. A new rating scale for Alzheimer's disease. Am J Psychiatry 1984; 149: 1356-1364.

20. Kraemer HC, Thiemann S. How many subjects? Statistical Power Analysis in Research. Newbury Park, CA: Sage, 1987.

21. Erzigkeit $H$. The SKT - a short cognitive performance test as an instrument for the assessment of clinical efficacy of cognitive enhancers. In: Bergner W, Reisberg B, eds. Diagnosis and Treatment of Senile Dementia. Heidelberg: Springer, 1989.

22. Folstein MF, Folstein SE, McHugh PR. Mini-Mental State: A practical method for grading the cognitive state of patients for the clinician. J Psychiatry Res 1975; 12: 189-195.

23. Lawton MP, Brody EM. Assessment of older people: self-maintaining and instrumental activities of daily living. Gerontologist 1969; 9: 176-186.

24. Baumgarten M, Becker R, Gauthier S. Validity and reliability of the dementia Behaviour Disturbance Scale. J Am Geriatric Soc 1990; 38: 221-226.

25. American Psychiatric Association. Diagnostic and Statistical Manual, 3rd ed., Revised. Washington: American Psychiatric Association, 1987

26. McKhann G, Drachman D, Folstein M, et al. Clinical diagnosis of Alzheimer's disease: report of the NINCDS-ADRADA Work Group under the auspices of Department of Health and Human Services Task Force on Alzheimer's Disease. Neurology 1984; 34: 939-944.

27. Hachinski VC, Iliff LD, Zilhka E, et al. Cerebral blood flow in dementia. Arch Neurol 1975; 32; 632-637.
28. SAS Institute Inc. SAS/STAT Ser's Guide, Version 6, 4th ed. Cary, NC: SAS Institute Inc, 1989.

29. Mohr E, Feldman H, Gauthier S. Canadian guidelines for the development of antidementia therapies: a conceptual summary. Can J Neurol Sci 1995; 22: 62-71.

30. Rockwood K. Use of global assessment measures in dementia drug trials. J Clin Epidemiol 1994; 47: 101-103.

31. Gill TM, Feinstein AR. A critical appraisal of the quality of life measurements. JAMA 1994; 272: 619-626.

32. Howard K, Rockwood K. Quality of life in Alzheimer's disease. Dementia 1995; 6: 113-116.

33. Rockwood K, Stolee P, Howard K, Mallery L. The use of Goal Attainment Scaling in an anti-dementia drug trial. Neuroepidemiology 1996; 15: 330-338.

34. Davis KL, Powchik P. Tacrine. Lancet 1995; 345: 625-630.

35. Pomponi M, Giocobini E, Brufani M. Present state and future development of the therapy of Alzheimer disease. Aging 1990; 2: 125-153.

36. O'Connor DW, Pollitt PA, Hyde JB, et al. The reliability and validity of the Mini-Mental State in a British community survey. J Psychiat Res 1989; 23: 87-96.

37. Brayne C, Calloway P. The association of education and socioeconomic status with the Mini-Mental State Examination and the clinical diagnosis of dementia in elderly people. Age Ageing 1990; 19: 91-96.

38. Gagnon M, Letenneur L, Dartigues J-F, et al. Validity of the MiniMental State Examination as a screening instrument for cognitive impairment and dementia in French elderly community residents. Neuroepidemiology 1990; 9: 143-150.

39. Uhlmann FR, Larson EB. Effect of education on the Mini-Mental State Examination as a screening test for dementia. J Am Geriartr Soc 1991; 41: 1886-1892.

40. Jagger C, Clarke M, Anderson J. Screening for dementia - a comparison of two tests using receiver operating characteristic (ROC) analysis. Int J Geriatr Psychiatry 1992; 7: 659-665.

41. Ritchie K, Fuhrer R. A comparitive study of the performance of screening tests for senile dementia using receiver operating characteristics analysis. J Clin Epidemiol 1992; 45: 627-637.

42. Kaufmann L, Rousseeuw P. Finding Groups in Data. An Introduction to Cluster Analysis. New York: Wiley, 1990. 